\title{
Is Cu60Ti10Zr30 a bulk glass-forming alloy?
}

Jiang, Jianzhong; Saida, J.; Kato, H.; Ohsuna, T.; Inoue, A.

\section{Published in:}

Applied Physics Letters

Link to article, DOI:

$10.1063 / 1.1581001$

Publication date:

2003

\section{Document Version}

Publisher's PDF, also known as Version of record

Link back to DTU Orbit

Citation (APA):

Jiang, J., Saida, J., Kato, H., Ohsuna, T., \& Inoue, A. (2003). Is Cu60Ti10Zr30 a bulk glass-forming alloy? Applied Physics Letters, 82(23), 4041-4043. https://doi.org/10.1063/1.1581001

\section{General rights}

Copyright and moral rights for the publications made accessible in the public portal are retained by the authors and/or other copyright owners and it is a condition of accessing publications that users recognise and abide by the legal requirements associated with these rights.

- Users may download and print one copy of any publication from the public portal for the purpose of private study or research.

- You may not further distribute the material or use it for any profit-making activity or commercial gain

- You may freely distribute the URL identifying the publication in the public portal

If you believe that this document breaches copyright please contact us providing details, and we will remove access to the work immediately and investigate your claim. 


\title{
Is $\mathrm{Cu}_{60} \mathrm{Ti}_{10} \mathrm{Zr}_{30}$ a bulk glass-forming alloy?
}

\author{
J. Z. Jiang ${ }^{\text {a) }}$ \\ Department of Physics, Building 307, Technical University of Denmark, DK-2800 Lyngby, Denmark
}

J. Saida, H. Kato, T. Ohsuna, and A. Inoue

Institute for Materials Research, Tohoku University, Sendai 980-8577, Japan

(Received 21 November 2002; accepted 7 April 2003)

\begin{abstract}
The microstructures of $\mathrm{Cu}_{60} \mathrm{Ti}_{10} \mathrm{Zr}_{30}$ alloys fabricated by using two different methods, (rods of 2.5 $\mathrm{mm}$ in diameter prepared by a copper-mold casting method, and ribbons of about $0.03 \mathrm{~mm}$ in thickness prepared by the melt-spinning method), have been investigated by transmission electron microscopy and high-resolution transmission electron microscopy. Surprisingly, we found that the alloy in both geometries contains cubic nanometer-sized crystals of about 5-7 $\mathrm{nm}$ in diameter with a lattice parameter of $0.45 \mathrm{~nm}$ for ribbons and $7-15 \mathrm{~nm}$ in diameter with a lattice parameter of 0.42 $\mathrm{nm}$ for rods. Nanocrystals with a significant volume fraction are randomly distributed in the amorphous matrix. The copper element is enriched in nanocrystals while a slightly high zirconium content is found in the matrix. We classify that the $\mathrm{Cu}_{60} \mathrm{Ti}_{10} \mathrm{Zr}_{30}$ alloy prepared by both of the aforementioned methods is a nanocomposite: Nanocrystals embedded in an amorphous matrix.

(C) 2003 American Institute of Physics. [DOI: 10.1063/1.1581001]
\end{abstract}

$\mathrm{Cu}$-rich bulk metallic glasses were reported in a $\mathrm{Cu}-\mathrm{Ti}-$ $\mathrm{Zr}-\mathrm{Ni}$ system $^{1}$ and then in $\mathrm{Cu}-\mathrm{Ti}-\mathrm{Zr}-\mathrm{Ni}-\mathrm{Si}$ and $\mathrm{Cu}-\mathrm{Ti}-$ $\mathrm{Zr}-\mathrm{Ni}-\mathrm{Sn}$ systems. ${ }^{2,3}$ Recently, it was reported that bulk glassy alloys with a diameter of $4 \mathrm{~mm}$ can be formed in ternary $\mathrm{Cu}_{60} \mathrm{Ti}_{10} \mathrm{Zr}_{30}$ and $\mathrm{Cu}_{60} \mathrm{Ti}_{15} \mathrm{Hf}_{25}$ systems. ${ }^{4,5}$ Such materials exhibit good mechanical properties: Young's modulus is $114-134 \mathrm{GPa}$, the compressive yield strength; $1785-2010$ $\mathrm{MPa}$, the compressive fracture strength; 2150-2160 MPa, the tensile yield strength; $1780-1920 \mathrm{MPa}$, the tensile fracture strength; 2000-2130 MPa, the elastic elongation; $1.5 \%-$ $2.0 \%$, and the compressive plastic elongation; $0.8 \%-1.7 \% .^{5}$ An x-ray diffraction (XRD) technique is often applied to verify the amorphous state. However, for systems with very small crystals (less than $10 \mathrm{~nm}$ ) embedded in an amorphous matrix, XRD measurements may not be able to verify the microstructure. Instead, electron microscopy techniques, e.g., transmission electron microscopy (TEM) and high-resolution TEM (HRTEM), should be used. In this letter, we report TEM and HRTEM measurements of $\mathrm{Cu}_{60} \mathrm{Ti}_{10} \mathrm{Zr}_{30}$ alloys fabricated by using two different methods: As-cast rods of 2.5 $\mathrm{mm}$ in diameter prepared by a copper-mold casting method, and as-spun ribbons of about $0.03 \mathrm{~mm}$ in thickness prepared by the melt-spinning method.

Alloy ingots with composition $\mathrm{Cu}_{60} \mathrm{Ti}_{10} \mathrm{Zr}_{30}$ were prepared by arc melting of the pure metals (99.99\% copper, 99.9\% zirconium, and $99.9 \%$ titanium) in a purified argon atmosphere. Cylindrical samples of $2.5 \mathrm{~mm}$ in diameter (hereafter called rods) and ribbon samples with a cross section of $0.03 \times 1 \mathrm{~mm}^{2}$ (hereafter called ribbons) were prepared by a copper-mold casting method and a single-roller meltspinning method with a speed of $40 \mathrm{~m} / \mathrm{s}$, respectively. XRD measurements were carried out with $\mathrm{Cu} K \alpha$ radiation. Thermal analyses were performed in a Seiko DSC6300 differen-

\footnotetext{
a) Author to whom correspondence should be addressed; electronic mail: jiang@fysik.dtu.dk
}

tial scanning calorimeter (DSC) at a heating rate of $40 \mathrm{~K} / \mathrm{min}$ under a flow of purified argon. The microstructures of the alloy were examined by using field-emission HRTEM with an accelerating voltage of $300 \mathrm{kV}$ (JEOL JEM-3000F). The compositional analysis was performed by nanobeam energy dispersive x-ray spectroscopy (EDX) and high-angle annular detector dark-field scanning transmission electron microscopy (HAADF-STEM). TEM specimens were prepared by low-energy ion milling at $2.5 \mathrm{kV}$ and $5 \mathrm{~mA}$ with liquidnitrogen cooling.

Figure 1 shows XRD patterns of an as-cast rod and an as-spun ribbon of the $\mathrm{Cu}_{60} \mathrm{Ti}_{10} \mathrm{Zr}_{30}$ alloy. In both samples, the pattern consists of just one broad peak at $2 \theta \approx 40^{\circ}$ with a width of about $5.5^{\circ}$ at the appearance of the half maximum. No diffraction peaks from crystalline phases are detected. Figure 2 shows DSC curves of $\mathrm{Cu}_{60} \mathrm{Ti}_{10} \mathrm{Zr}_{30}$ alloys in ribbon and rod geometries. The alloys exhibit an endothermic event, characterized by a glass transition temperature $T_{g}=714 \mathrm{~K}$ for

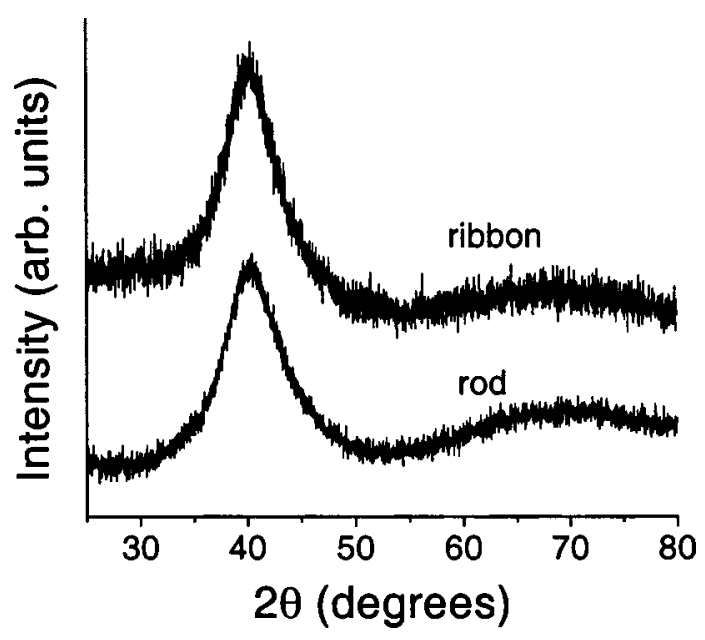

FIG. 1. XRD patterns recorded for as-cast rod and as-spun ribbon of the $\mathrm{Cu}_{60} \mathrm{Ti}_{10} \mathrm{Zr}_{30}$ alloy. 


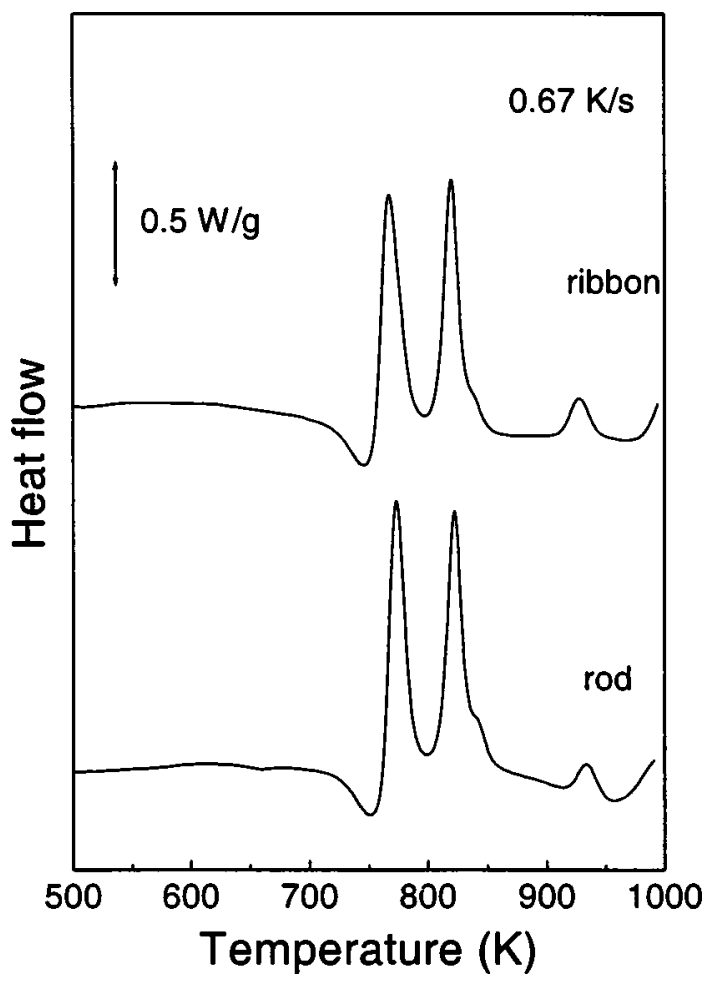

FIG. 2. DSC curves of as-cast rod and as-spun ribbon of the $\mathrm{Cu}_{60} \mathrm{Ti}_{10} \mathrm{Zr}_{30}$ alloy at a heating rate of $0.67 \mathrm{~K} / \mathrm{s}$ under a flow of purified argon.

the $\operatorname{rod}$ and $T_{g}=711 \mathrm{~K}$ for the ribbon, followed mainly by two exothermic events, indicating a two-stage phase transformation process, characterized by $T_{x 1}=758 \mathrm{~K}$ and $T_{x 2}=807$ $\mathrm{K}$ for the rod and $T_{x 1}=754 \mathrm{~K}$ and $T_{x 2}=804 \mathrm{~K}$ for the ribbon. The XRD patterns, and the values of $T_{g}, T_{x 1}$, and $T_{x 2}$ for the $\mathrm{Cu}_{60} \mathrm{Ti}_{10} \mathrm{Zr}_{30}$ alloy are in good agreement with literature data. ${ }^{4,5}$ Figure 3 shows the TEM bright-field image, HRTEM image, and selected-area electron diffraction pattern of the as-cast $\mathrm{Cu}_{60} \mathrm{Ti}_{10} \mathrm{Zr}_{30}$ rod. The TEM image [Fig. 3(a)] shows that the sample is composed of gray regions and a bright matrix. The gray regions have sizes in the range of 7-15 nm and represent a significant volume fraction $(>5 \%)$. Note that it is very hard to determine the true volume fraction from TEM images. The HRTEM image [Fig. 3(b)] reveals that most gray regions show lattice fringes, indicating a crystalline phase. The diffraction pattern [Fig. 3(c)] further confirms the crystalline state in some gray regions (cubic structure, lattice parameter about $0.42 \mathrm{~nm}$ ), while the bright matrix has an amorphous structure. $\mathrm{Cu}$ enhancement in the nanocrystals and depletion in the amorphous matrix are manifested as shown in Fig. 4. Chemical compositions of several nanometer-sized gray regions and of the amorphous matrix in the as-cast rod and as-spun ribbon were estimated by nanobeam EDX with a beam size of about $5 \mathrm{~nm}$. The
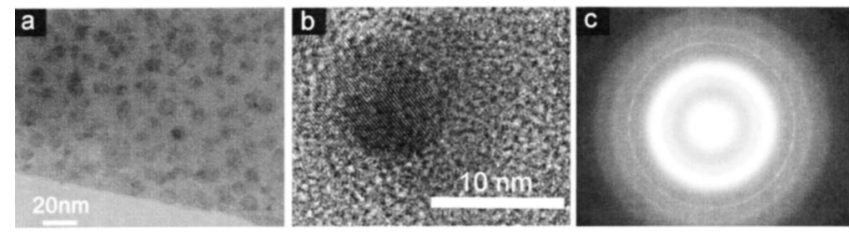

FIG. 3. TEM bright-field image (a), HRTEM image (b), and selected-area electron diffraction patterns (c) of the as-cast $\mathrm{Cu}_{60} \mathrm{Ti}_{10} \mathrm{Zr}_{30}$ rod.

Downloaded 26 Mar 2010 to 192.38.67.112. Redistribution subject to AIP license or copyright; see http://apl.aip.org/apl/copyright.jsp

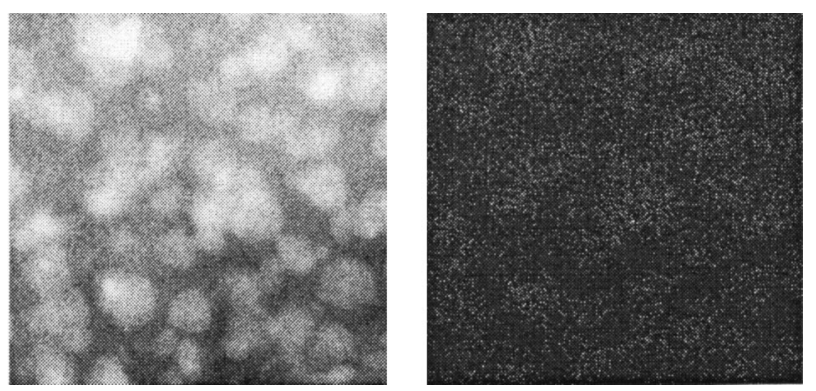

FIG. 4. TEM dark-field image and copper element mapping image obtained from the same area as the TEM dark-field image by EDX of the as-cast $\mathrm{Cu}_{60} \mathrm{Ti}_{10} \mathrm{Zr}_{30}$ rod.

results are listed in Table I. The average copper content in the nanocrystals is about $70.5 \%$ for the rod sample, indeed, higher than the average copper content of the sample as a whole, while it is only $44.0 \%$ in the amorphous matrix. The results are in agreement with the copper mapping image in Fig. 4.

One might argue that during the copper-mold casting, the cooling rate may be not high enough to achieve a homogeneous single amorphous phase in the $\mathrm{Cu}_{60} \mathrm{Ti}_{10} \mathrm{Zr}_{30}$ rod sample. How about a ribbon sample, which is prepared by the melt-spinning method with a high cooling rate $>10^{4}$ $\mathrm{K} / \mathrm{s}$ ? In fact, in the $\mathrm{Cu}_{47} \mathrm{Ti}_{34} \mathrm{Zr}_{11} \mathrm{Ni}_{8}$ alloy, the cooling rate effect on the formation of nanocrystals was reported. ${ }^{6,7}$ In order to answer this question, we further carried out an electron microscopic investigation of the as-spun $\mathrm{Cu}_{60} \mathrm{Ti}_{10} \mathrm{Zr}_{30}$ ribbon. Surprisingly, similar microstructure features were also observed for the ribbon as shown in Fig. 5. The image

TABLE I. Chemical composition of several nanocrystals and the amorphous matrix in the as-cast rods and as-spun ribbons estimated by nanobeam EDX facility with a beam size of about $5 \mathrm{~nm}$.

\begin{tabular}{|c|c|c|c|c|}
\hline Sample & Component & $\begin{array}{c}\mathrm{Cu} \\
(\text { at. \%) }\end{array}$ & $\begin{array}{c}\mathrm{Ti} \\
\text { (at. \%) }\end{array}$ & $\begin{array}{c}\mathrm{Zr} \\
\text { (at. \%) }\end{array}$ \\
\hline \multirow[t]{11}{*}{ Rod } & \multirow[t]{5}{*}{ Nanocrystal } & 70.8 & 5.5 & 23.8 \\
\hline & & 75.8 & 4.7 & 19.5 \\
\hline & & 56.4 & 6.6 & 36.9 \\
\hline & & 72.4 & 5.1 & 22.5 \\
\hline & & 77.1 & 4.0 & 18.9 \\
\hline & Average & 70.5 & 5.2 & 24.3 \\
\hline & \multirow[t]{3}{*}{ Amorphous matrix } & 39.4 & 13.8 & 46.7 \\
\hline & & 44.2 & 9.9 & 45.9 \\
\hline & & 48.3 & 7.4 & 44.3 \\
\hline & Average & 44.0 & 10.4 & 45.6 \\
\hline & $\begin{array}{l}\text { An area } \\
\left(1 \mu \mathrm{m}^{2}\right)\end{array}$ & 58.6 & 9.1 & 32.2 \\
\hline \multirow[t]{13}{*}{ Ribbon } & \multirow[t]{5}{*}{ Nanocrystal } & 67.7 & 5.8 & 26.5 \\
\hline & & 71.2 & 5.3 & 23.5 \\
\hline & & 70.9 & 4.7 & 24.4 \\
\hline & & 65.7 & 6.0 & 28.3 \\
\hline & & 68.1 & 5.9 & 26.0 \\
\hline & Average & 68.8 & 5.5 & 25.7 \\
\hline & \multirow[t]{5}{*}{ Amorphous matrix } & 59.3 & 7.7 & 33.0 \\
\hline & & 51.2 & 9.2 & 39.6 \\
\hline & & 55.0 & 8.0 & 37.0 \\
\hline & & 54.6 & 8.5 & 36.9 \\
\hline & & 60.4 & 8.1 & 31.5 \\
\hline & Average & 56.1 & 8.3 & 35.6 \\
\hline & $\begin{array}{l}\text { An area } \\
\left(1 \mu \mathrm{m}^{2}\right)\end{array}$ & 61.4 & 8.3 & 30.3 \\
\hline
\end{tabular}



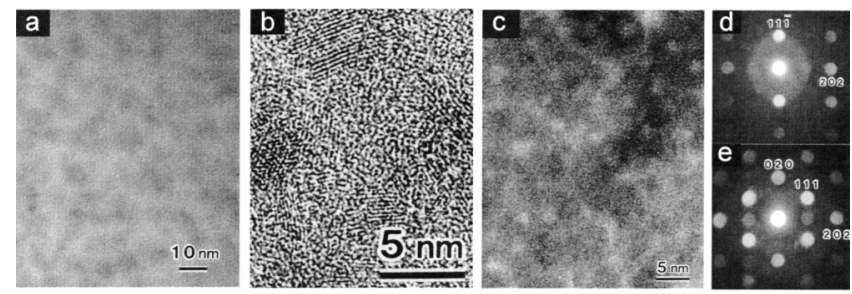

FIG. 5. TEM bright-field image (a), HRTEM image (b), Z-contrast image (c), and nanobeam electron diffraction patterns $[(\mathrm{d})$ and (e)] of the as-spun $\mathrm{Cu}_{60} \mathrm{Ti}_{10} \mathrm{Zr}_{30}$ ribbon.

consists of both gray and bright areas with a size of about 5-7 nm [Fig. 5(a)]. Small crystals are clearly detected in the HRTEM image [Fig. 5(b)]. Furthermore, the HAADF-STEM (Z-contrast) image [Fig. 5(c)] depicts a significant compositional fluctuation, brighter regions resulting from a relatively higher concentration of heavy $\mathrm{Zr}$ atoms since the thickness is regarded as a constant due to the very small beam cross section of HAADF-STEM. The nanobeam electron diffraction patterns using a beam diameter of $2.4 \mathrm{~nm}$ reveal a cubic structure with a lattice parameter of approximately $0.45 \mathrm{~nm}$. The zone axis is parallel to $[1 \overline{2} \overline{1}]$ in Fig. 5(d) and [10 $\overline{1}]$ in Fig. 5(e). From Table I, it is seen that $\mathrm{Cu}$ is enriched in the nanocrystals and depleted in the amorphous matrix in both the ribbon sample, and the rod sample. It seems that the volume fraction of nanocrystals is smaller in the ribbon sample than in the rod sample.

To uncover the nature of why the $\mathrm{Cu}_{60} \mathrm{Ti}_{10} \mathrm{Zr}_{30}$ alloy system exhibits such a microstructure, we further measured oxygen impurity in our ribbon and rod samples. It was found that they have a similar level around 800-1200 ppm, which is most likely introduced by $\mathrm{Ti}$ and $\mathrm{Zr}$ elements. Oxygen could work as a heterogeneous nucleation site to promote the formation of nanocrystals. On the other hand, a relative low oxygen impurity detected in our samples suggests that the possibility of oxygen-driven nucleation as the main factor for the formation of nanocrystals with a significant volume might be small. From the $\mathrm{Cu}-\mathrm{Ti}-\mathrm{Zr}$ phase diagram obtained from a liquid project, ${ }^{8}$ at least three eutectic compositions exist with less than 50 at. \% of copper, i.e., (1) $\mathrm{Cu}_{48.63} \mathrm{Ti}_{14.24} \mathrm{Zr}_{37.13}$, (2) $\mathrm{Cu}_{39.43} \mathrm{Ti}_{17.37} \mathrm{Zr}_{43.20}$, and (3) $\mathrm{Cu}_{47.59} \mathrm{Ti}_{34.43} \mathrm{Zr}_{17.98}$. In the present work, we clearly observed that (1) in the amorphous matrix copper element is less than 60 at. \% while a slightly high zirconium content is found and (2) faster cooling results in smaller crystals and less crystal volume fraction. Together with literature data for the $\mathrm{Cu}_{47} \mathrm{Ti}_{34} \mathrm{Zr}_{11} \mathrm{Ni}_{8}$ alloy, ${ }^{6,7}$ in which slow cooling results in the formation of nanocrystals, we suggest that in the $\mathrm{Cu}_{60} \mathrm{Ti}_{10} \mathrm{Zr}_{30}$ alloy, composition inhomogeneity (or composition separation) in a nanometer-scale region could be favorable during solidification. Two different regions are formed, i.e., $\mathrm{Cu}$-rich and $\mathrm{Cu}$-poor regions. In the $\mathrm{Cu}$-rich region, the composition is far from the eutectic compositions mentioned herein so that the glass-forming ability may become low. Thus, nanocrystals are formed. In the $\mathrm{Cu}$-poor region, the composition is close to one of the eutectic compositions just mentioned, resulting in a high glass-forming ability and a single glassy phase. When the melt of $\mathrm{Cu}_{60} \mathrm{Ti}_{10} \mathrm{Zr}_{30}$ alloy is rapidly cooled, less time is available for atom diffusion. Consequently, composition inhomogeneity regions nanocrystals, and the volume fraction of the nanocrystals all become smaller. We might expect a pure single glassy phase of the $\mathrm{Cu}_{60} \mathrm{Ti}_{10} \mathrm{Zr}_{30}$ alloy using a high cooling rate.

In conclusion, microstructures of $\mathrm{Cu}_{60} \mathrm{Ti}_{10} \mathrm{Zr}_{30}$ alloys fabricated by using two different methods, (rods of $2.5 \mathrm{~mm}$ in diameter prepared by a copper-mold casting method, and ribbons of about $0.03 \mathrm{~mm}$ in thickness prepared by the meltspinning method), have been investigated by TEM, HRTEM, $\mathrm{XRD}$, and DSC. Surprisingly, we have found that the alloy in both geometries contains cubic nanometer-sized crystals of about 5-7 nm in diameter with a lattice parameter of 0.45 $\mathrm{nm}$ for ribbons and $7-15 \mathrm{~nm}$ in diameter with a lattice parameter of $0.42 \mathrm{~nm}$ for rods. The nanocrystals with significant volume fractions are randomly distributed in an amorphous matrix. Copper is enriched in nanocrystals while a slightly high zirconium content is found in the amorphous matrix. On the basis of the results obtained here, we conclude that the $\mathrm{Cu}_{60} \mathrm{Ti}_{10} \mathrm{Zr}_{30}$ alloy prepared by the two methods mentioned herein is a nanocomposite: Nanocrystals embedded in an amorphous matrix. It is still an unsolved problem as to why the XRD patterns recorded in Fig. 1 from the as-cast rod and as-spun ribbon do not clearly show some broad diffraction peaks for the about 5-10 vol \% nanocrystals. The microstructure of the $\mathrm{Cu}_{60} \mathrm{Ti}_{10} \mathrm{Zr}_{30}$ alloy presented here will certainly trigger further investigations to uncover the correlation between the microstructure and the excellent mechanical properties of the nanocomposite alloy.

Financial support from the Danish Technical Research Council, the Danish Natural Sciences Research Council, and the Japan Society for the Promotion of Science is gratefully acknowledged.

\footnotetext{
${ }^{1}$ X. H. Lin and W. L. Johnson, J. Appl. Phys. 78, 6514 (1995).

${ }^{2}$ T. Zhang and A. Inoue, Mater. Trans., JIM 40, 301 (1999).

${ }^{3}$ C. Li, J. Saida, M. Kiminami, and A. Inoue, J. Non-Cryst. Solids 261, 108 (2000).

${ }^{4}$ A. Inoue, W. Zhang, T. Zhang, and K. Kurosaka, Mater. Trans., JIM 42, 1149 (2001).

${ }^{5}$ A. Inoue, W. Zhang, T. Zhang, and K. Kurosaka, Acta Mater. 49, 2645 (2001).

${ }^{6}$ M. K. Miller, K. F. Russell, P. M. Martin, R. Busch, and W. L. Johnson, J. Phys. IV 6, 217 (1996).

${ }^{7}$ S. C. Glade, J. F. Loffler, S. Bossuyt, W. L. Johnson, and M. K. Miller, J. Appl. Phys. 89, 1573 (2001).

${ }^{8}$ C. G. Woychik and T. B. Massalski, Z. Metallkd. 79, 149 (1988).
} 